\title{
Utilization of insecticides treated mosquito bed nets among pregnant women in Kassena-Nankana East municipality in the upper east region of Ghana
}

\author{
Mubarick N. Asumah ${ }^{1,2}$, Francis A. Akugri ${ }^{3}$, Patricia Akanlu ${ }^{4}$, Alice Taapena ${ }^{4}$, Faustina Boateng ${ }^{4}$
}

\author{
AFFILIATION \\ 1 Department of Global and International Health, School of Public Health, University for Development Studies, Tamale, Ghana \\ 2 Ghana Health Service, Kintampo Municipal Hospital, Kintampo, Ghana \\ 3 Department of Preventive Health Nursing, School of Nursing and Midwifery, University for Development Studies, Tamale, Ghana \\ 4. Department of Midwifery and Women's Health, School of Nursing and Midwifery, University for Development Studies, Tamale, Ghana
}

CORRESPONDENCE TO

Mubarick N. Asumah. Department of Global and International Health, School of Public Health, University for Development Studies, P.0. Box TL1350, Tamale Northern Region, Ghana. E-mail: nungbaso.asumah@uds.edu.gh ORCID ID: https://orcid.org/0000-0001-6597-8059

\section{KEYWORDS}

insecticides treated mosquito bed nets (ITNS), malaria, pregnant women, utilization

Received: 27 October 2021, Revised: 30 November 2021, Accepted: 3 December 2021

Public Health Toxicol 2021;1(2):9

https://doi.org/10.18332/pht/144533

\section{ABSTRACT}

INTRODUCTION Malaria has threatened the lives of 3.2 billion individuals worldwide and has dire consequences on pregnant women and children. Insecticides Treated Mosquito Nets (ITNs) are the simplest way of preventing malaria. The main objective of this study was to assess the utilization of ITNs among pregnant women in the Kassena-Nankana East Municipality.

METHODS A descriptive cross-sectional study was used. The study recruited 362 pregnant women using simple random sampling technique. All statistics were performed at a $95 \%$ confidence level with $\mathrm{p}<0.05$ considered significant.

RESULTS Almost all (99.7\%) respondents had heard about mosquito bed nets, of which $98.6 \%$ have ever seen bed nets. The majority (96.2\%) of the respondents stated that ITNs could be obtained from health facilities and over $90 \%$ knew the general use of ITNs. The majority of the respondents (97.8\%) had mosquito bed nets. Out of those who owned ITNs, 94.8\% use them. Reasons for not using ITNs included the fact that some feel: not being necessary (26.2\%), being expensive, cannot afford it (15.8\%), inadequate public education (47.5\%), and difficulty in accessing ITNs (10.5\%). The study revealed a significant association between area of residence $\left(\chi^{2}=3.4 ; p=0.04\right)$, increasing average monthly income $\left(\chi^{2}=46.4 ; p<0.001\right)$, and utilization of ITNs.

CONCLUSIONS There is high awareness and knowledge about ITNs. Though the majority of the participants owned ITNs, it does not translate to effective utilization of ITNs. The challenges identified in this study showed that there are still fundamental issues that require immediate attention for the effective utilization of ITNs.

\section{INTRODUCTION}

Malaria is a disease that threatens the lives of 3.2 billion people throughout the world and has a cascading impact on pregnant women and children under the age of five ${ }^{1}$. Malaria is one of the leading causes of illness, mortality, poverty, and low productivity, among the majority of people living in lowto middle-income countries (LMICs) ${ }^{2}$. Malaria increases the risk of serious pregnancy complications for the mother, fetus, and newborn ${ }^{3}$. Insecticide-treated bed nets (ITNs) are a type of personal protection that has been proved to minimize malaria infection, severe disease, and death ${ }^{4}$. The effective use of ITNs has reduced malaria sickness by $50 \%$ in children aged $<5$ years, and reduced mortality by $17 \%{ }^{5}$. The WHO Roll Back Malaria (RBM) project, which began in 1998, intended to prevent and control malaria during pregnancy via the use of ITNs and other measures ${ }^{4}$. In a meta-analysis of malaria-prevention datasets from several African countries, it was discovered that ITNs are critical in avoiding malaria in pregnancy ${ }^{3}$. Miscarriages and stillbirths are reduced by roughly $33 \%$ when ITNs are used throughout pregnancy ${ }^{6}$. 
In Ethiopia, 39\% of pregnant women did not have a positive attitude towards ITNs ${ }^{7}$. In the Democratic Republic of Congo, about $82 \%$ reported having an ITN in their household, of these only $78.4 \%$ used ITNs the night before the study survey ${ }^{8}$. In Sudan, the ownership of ITNs was nearly $57 \%$, however, only $11.5 \%$ used ITNs frequently 9 . About $92 \%$ demonstrated sufficient knowledge on the cause of malaria, and $60 \%$ exhibited appreciable knowledge on the reasons why ITNs are used. Despite the above, only $22.1 \%$ knew the correct usage of ITNs ${ }^{9}$.

Ghana is one of the world's fifteen countries with the greatest malaria infection rate ${ }^{10}$. Malaria infection is among the ten topmost diseases in Ghana ${ }^{11}$. Malaria affects all people, but it is common with expectant mothers and babies with very dire consequences ${ }^{12}$. Ghana saw the biggest increase in absolute case counts (about 0.5 million new cases) between 2017 and 2018, indicating a 5\% increase over 2017 levels (from 213 to 224 per 1000 at risk) ${ }^{2}$. In Sub-Saharan Africa, Ghana has the highest incidence of Intermittent Preventive Treatment in Pregnancy (IPTp) for pregnant women (78\%). The percentage of pregnant women taking the third dosage of IPTp climbed from 39\% to $60 \%$ in 2016, to $61 \%$ in $2019^{13}$. IPTp involves giving all pregnant women a curative dose of an effective antimalarial medicine (now sulfadoxine-pyrimethamine) without first determining whether or not they have malaria. It is recommended that pregnant women take at least three doses of IPTp starting from second trimester till birth ${ }^{14}$.

The intentional campaign and intervention on ITNs have resulted in a rise in household ownership of ITNs from $49 \%$ in 2011 to $68 \%$ in 20146,15 . In Ghana, the usage of ITNs among pregnant women grew from roughly 33\% in 2011 to $43 \%$ in 2014. Lack of availability of ITNs, as well as a lack of information and perception about ITNs and malaria, have previously been identified as significant hurdles to ITN adoption in Africa ${ }^{16}$. Indication from Ghana has shown that over $40 \%$ of ITNs available in the households go unused ${ }^{17}$. A study conducted in the middle belt of Ghana showed that pregnant women knew how crucial ITNs are to preventing malaria. Some pregnant women due to financial constraints, and missed chance during the free distribution of ITNs, do not own a bed net and do not sleep under one. Aside from the above genuine excuses, some of the pregnant women were also not using ITNs because of discomfort resulting from heat, the smell of the net, and difficulty in hanging the net ${ }^{18}$.

Despite the progress achieved in carrying out active preventive and treatment measures, malaria is still very prevalent in Ghana. Malaria accounts for 38.1\% of all outpatient department cases and more than half of all hospital admissions in Ghana among children aged $<5$ years. Malaria infection is responsible for about half of all fatalities among children aged $<5$ years in Ghana ${ }^{19}$. Available literature in Ghana has demonstrated that the most households who own bed nets, do not sleep under them ${ }^{20}$. In addition, research performed in seven districts of Ghana's Upper East region found that while $79 \%$ of pregnant women had bed nets, only $62 \%$ utilized them the night before the survey ${ }^{15}$. In addition to the above, there is a vast difference with regard to the utilization of bed nets between urban and rural areas of Ghana ${ }^{20}$.

Ghana is still working to achieve universal ITN coverage (defined as use by $80 \%$ or more of the population in an endemic region) to provide the best possible protection ${ }^{4}$. As a result, continuous monitoring and assessment of access to and use of treated bed nets are required to guide malaria control policy and practice, particularly in high-risk parts of the nation. There are vast studies on ITNs utilization in Ghana but most are often in the urban settings ${ }^{17,20-22}$ with limited studies in deprived areas ${ }^{23}$. Malaria prevention especially among pregnant women and children aged $<5$ years is a topmost priority for the Ghana government. As such, studies across the countries are required to inform policy decisions aimed at eradicating or reducing malaria infection among the general population. The Kassena-Nankana East Municipality is mostly rural with no study conducted in this area on ITN usage. To bridge this gap, this study aims to assess the utilization of Insecticides Treated Mosquito Nets (ITNs) among pregnant women in Kassena-Nankana East Municipality in the Upper East Region of Ghana.

\section{METHODS}

\section{Study setting}

The study setting was conducted in the Kassena-Nankana East Municipality, which was upgraded by legislative instrument (LI) 2106 from the District level in 2012. The municipality has Navrongo as its political and administrative capital. The study setting was chosen because the municipality is predominately rural with no study conducted on ITN.

\section{Study design}

The study employed a descriptive cross-sectional survey with a quantitative approach to explore the utilization of ITNs among pregnant women in Kassena-Nankana East from May to July 2021.

\section{Inclusion and exclusion criteria}

The study included pregnant women who resided in the Kassena-Nankana East Municipality, who were of sound mind, and agreed to participate in the study voluntarily. All other persons who were outside these criteria were excluded including pregnant women who were on admission.

Sample size determination, sampling techniques, and procedure

The sample size was computed using the Snedecor and Cochran ${ }^{24}$ formula for a point estimate sample. The utilization of ITNs among pregnant women was $62 \%{ }^{23}$. From the Snedecor and Cochran formula, the sample size was calculated as 362 . All communities with a hospital, health 
center or community-based health planning and service (CHPS) center, were all written on pieces of paper, and ten health facilities were chosen at random without replacement. The study used simple random sampling in recruiting the sample unit in each facility. Thus, for each of the communities (health facilities) visited, 30 pregnant women were recruited at random, except the District Hospital where 92 pregnant women were recruited. The District Hospital serves as a referral center for all the other facilities and most pregnant women choose to go there for their ANC irrespective of the distance.

\section{Data collection tools and procedures}

The questionnaire was adapted from existing literature en, $^{15,26}$ and modified to suit the study objectives (Supplementary file Questionnaire). The questionnaire was structured for the specific objectives of the study consisting of Section A: Sociodemographic data of the respondents; Section B: knowledge on ITNs; Section C: utilization of ITNs; and Section D: barriers to the use of ITNs as a preventive and control tool against malaria among pregnant women. The questions were both open and close-ended.

The study explored the use of self-administered questionnaire techniques. A total of six field assistants were trained on the data collection tool to gather the data within the shortest possible time. Data collectors were also trained on the simple random sampling procedure for the selection of respondents.

\section{Reliability and validity of the study}

To ensure that the data collected were reliable and valid, the field enumerators were trained on the use of data collection tools. Thirty pregnant women in Paga (a community similar to the study area) were interviewed during pretesting (piloting). Pre-testing helped in restructuring the questionnaire to elicit the right response for the specific objective. It also offered the field enumerators the chance to familiarize themselves with the data collection process and to rectify all difficulties before the main data collection process. For the validity of this study, the questionnaires were asked in plain language to solicit the right response. The questionnaire was also shown to experienced researchers in the area for face validity. The Supplementary file Dataset contains a dataset from the pre-testing (piloting). Internal consistency (reliability) of the measurement scales of the instrument was computed using Cronbach's alpha. The overall alpha of the instrument was $\alpha=0.81$ while the alpha values for the scales of knowledge, utilization and barriers of ITNs were $\alpha=0.86, \alpha=0.89$ and $\alpha=0.68$, respectively. The overall alpha was considered as good.

\section{Data analysis and presentation}

Data were analyzed using SPSS version 25.0. Data are presented using descriptive and inferential statistics. Chisquared analysis was used to determine the statistical association between background characteristics and ITN utilization. All statistics were performed at a 95\% confidence level, and $\mathrm{p}<0.05$ was considered significant.

\section{RESULTS}

\section{Sociodemographic characteristics}

Most (46.4\%) of the respondents were aged 30-39 years. Over $90 \%$ of the respondents had some level of education, with only $9.10 \%$ not having gone to school. A majority, $64.9 \%, 87.6 \%$, and $52.2 \%$ of the respondents were Christians, married, and resided in rural areas, respectively (Table 1).

\section{Knowledge on ITNs}

Almost all (99.7\%) respondents had ever heard of ITNs, of which $98.6 \%$ had seen and handled mosquito bed nets.

\section{Table 1. Sociodemographic characteristics of the participants}

\begin{tabular}{|c|c|c|}
\hline Characteristics & $\mathrm{n}$ & $\%$ \\
\hline \multicolumn{3}{|l|}{ Age (years) } \\
\hline$<20$ & 72 & 19.90 \\
\hline $20-29$ & 92 & 25.40 \\
\hline 30-39 & 168 & 46.40 \\
\hline$\geq 40$ & 30 & 8.30 \\
\hline
\end{tabular}

\section{Education level}

No formal education

$33 \quad 9.10$

Junior high school and below

137

37.80

Senior high school

Tertiary

101

27.90

\section{Religion}

Christianity

235

64.90

Islam

125

34.50

Traditionalist

2

0.60

\section{Marital status}

Single 33 9.10

Cohabiting

Married 317 87.60

Divorced

Separated

4

1.10

\section{Occupation}

Trader

Farmer

Teacher

Health worker

Housewife 
Table 1. Continued

\begin{tabular}{lrr} 
Characteristics & n & $\%$ \\
\hline Seamstress & 16 & 4.40 \\
Students & 14 & 3.90 \\
Hairdresser & 9 & 2.50 \\
Other & 9 & 2.50 \\
Number of children & & \\
\hline $1-2$ & 259 & 71.50 \\
$3-4$ & 85 & 23.50 \\
5-6 & 17 & 4.70 \\
$>6$ & 1 & 0.30 \\
Area of residence & & \\
Rural & 189 & 52.20 \\
Urban & 173 & 47.80 \\
Average monthly income (GHS) & & \\
$<500$ & 181 & 50.00 \\
500-1000 & 98 & 27.10 \\
1001-1500 & 62 & 17.10 \\
1501-2000 & 15 & 4.10 \\
$>$ 2000 & 6 & 1.70 \\
Ethnicity & & \\
Frafra & 174 & 48.10 \\
Nankam & 16 & 4.40 \\
Kassena & 3.10 \\
Builsa & 79 & 16.00 \\
Mamprusi & & \\
\hline & & \\
\hline
\end{tabular}

GHS: 1000 Ghanaian Cedis about US $\$ 160$

Sources of information on ITNs included: media (radio/ television) 91.4\% (331), health workers 271 (74.9\%), friends $100(27.6 \%)$, and books/journals 70 (19.3\%). Over half $(50.8 \%)$ of respondents knew that ITNs are used to prevent malaria. The majority (89.0\%) of respondents dried their ITNs in the shade before using them. On whether ITNs can be retreated, $71.3 \%$ agreed (Table 2 ).

\section{Utilization of ITNS}

The majority (97.8\%) of respondents owned mosquito bed nets. Of these, $94.8 \%$ used their nets. Majority $(90.3 \%)$ of respondents have been beneficiaries of free distribution of ITNs from health workers $(69.1 \%)$ and their friends (30.9\%). Of the main reason for using an ITN, $84.0 \%$ believe it prevents malaria, $14.4 \%$ believe it prevents insect bites, and $1.7 \%$ believed it prevents mosquito nuisance. The majority (89.0\%) of the respondents slept under ITNs the previous night while $11.0 \%$ did not sleep under ITNs the
Table 2. Knowledge on insecticide treated mosquito nets (ITNs)

\begin{tabular}{|c|c|c|}
\hline Variables & n & $\%$ \\
\hline \multicolumn{3}{|l|}{ Ever heard of ITNs } \\
\hline Yes & 361 & 99.70 \\
\hline No & 1 & 0.30 \\
\hline \multicolumn{3}{|c|}{ Ever seen or handled ITNs } \\
\hline Yes & 357 & 98.60 \\
\hline No & 5 & 1.40 \\
\hline \multicolumn{3}{|c|}{ Sources of information on ITNs* } \\
\hline Media (radio/television) & 331 & 91.40 \\
\hline Health workers & 271 & 74.90 \\
\hline Friends & 100 & 27.60 \\
\hline Books/journal & 70 & 19.30 \\
\hline \multicolumn{3}{|l|}{ Where to get ITNs } \\
\hline Cosmetic stores & 5 & 1.40 \\
\hline Health facilities & 348 & 96.20 \\
\hline Super market & 9 & 2.50 \\
\hline \multicolumn{3}{|l|}{ Uses of ITNs } \\
\hline To avoid mosquito bites & 184 & 50.80 \\
\hline To have a good night & 5 & 1.40 \\
\hline To prevent malaria & 173 & 47.80 \\
\hline \multicolumn{3}{|c|}{ How long does ITN effectiveness last } \\
\hline$<6$ months & 69 & 19.10 \\
\hline $6-12$ months & 30 & 8.30 \\
\hline More than a year & 85 & 23.50 \\
\hline 3 years & 131 & 36.20 \\
\hline$<5$ years & 2 & 0.60 \\
\hline
\end{tabular}

What is done before first usage of an ITN

Dry it in the shade

$322 \quad 89.00$

Dry it in the sun

25

6.90

Wash it

15

4.10

\section{Can ITNs be retreated}

Yes

No

\section{When to retreat ITNs*}

After washing once

After you have a mosquito bite despite

sleeping in an ITN

After 3 to 5 years of usage

225

62.20

After washing 3 times

48.60

When it is dirty

*Multiple response. 
Table 3. Utilization of insecticides treated mosquito bed nets (ITNS)

\begin{tabular}{|c|c|c|}
\hline Variables & n & $\%$ \\
\hline \multicolumn{3}{|l|}{ Do you have an ITN } \\
\hline Yes & 354 & 97.80 \\
\hline No & 8 & 2.20 \\
\hline \multicolumn{3}{|l|}{ Do you use an ITN } \\
\hline Yes & 343 & 94.80 \\
\hline No & 19 & 5.20 \\
\hline \multicolumn{3}{|l|}{$\begin{array}{l}\text { Ever been a beneficiary of free } \\
\text { distribution of ITNs }\end{array}$} \\
\hline Yes & 327 & 90.30 \\
\hline No & 35 & 9.70 \\
\hline \multicolumn{3}{|l|}{ From whom did you benefit } \\
\hline Health worker & 226 & 69.10 \\
\hline Friend & 101 & 30.90 \\
\hline \multicolumn{3}{|l|}{ What type of ITN do you have } \\
\hline Ever treated nets & 5 & 1.40 \\
\hline Insecticide-treated mosquito nets & 191 & 52.80 \\
\hline Long-lasting insecticide nets & 147 & 40.60 \\
\hline Ordinary nets & 11 & 3.00 \\
\hline Don't know & 8 & 2.20 \\
\hline \multicolumn{3}{|l|}{ Main reason for using ITNs } \\
\hline Prevent insect bites & 52 & 14.40 \\
\hline Prevent malaria & 304 & 84.00 \\
\hline Prevent mosquito nuisance & 6 & 1.70 \\
\hline \multicolumn{3}{|c|}{$\begin{array}{l}\text { Level of ITN protection in terms of } \\
\text { preventing malaria among pregnant } \\
\text { women }\end{array}$} \\
\hline Average & 7 & 1.90 \\
\hline Effective & 68 & 18.80 \\
\hline Very effective & 268 & 74.00 \\
\hline Not effective at all & 1 & 0.30 \\
\hline I don't know & 18 & 4.90 \\
\hline \multicolumn{3}{|l|}{ Slept under ITN last night } \\
\hline Yes & 322 & 89.00 \\
\hline No & 40 & 11.00 \\
\hline
\end{tabular}

\section{How consistently do you (pregnant} women) sleep under ITNs

Throughout the night during the season $\quad 121 \quad 33.40$ for mosquitoes

All year round

$170 \quad 47.00$

Most of the night

$55 \quad 15.10$

Once in a while

$10 \quad 2.80$

I don't know

6

If ITNs are readily available, would you consider using them daily

Yes

No

302

83.40

Sometimes previous night. Most (47.0\%) of the respondents sleep under ITNs throughout the year, and the majority (83.4\%) of respondents would consider using the ITNs if they are readily made available (Table 3).

\section{Barriers to the use of ITNs as a preventive and control tool against malaria}

The majority (96.1\%) of the respondents would recommend ITNs to others. Reasons for not using an ITN include: it being unnecessary (26.2\%), being expensive and unaffordable (15.8\%), inadequate public education (47.5\%), and difficulty in accessing an ITN (10.5\%). Other barriers included: cultural belief $(2.20 \%)$, personal reaction after sleeping under an ITN (14.9\%), and the discriminatory attitude of health workers against their household (5.2\%). The majority (51.9\%) of the respondents complained of body itching when they used ITNs, 31.5\% mentioned body rashes, and $16.6 \%$ mentioned body sensation as a personal reaction upon using ITNs (Table 4).

Table 4. Barriers to the use of insecticides treated mosquito bed nets (ITNs) as a preventive and control tool against malaria among pregnant women

\begin{tabular}{|c|c|c|}
\hline Variables & n & $\%$ \\
\hline \multicolumn{3}{|c|}{$\begin{array}{l}\text { Reasons you did not use ITN last night } \\
(n=40)^{*}\end{array}$} \\
\hline Don't feel comfortable under it & 23 & 57.50 \\
\hline Not effective & 2 & 5.00 \\
\hline Side effects & 8 & 20.00 \\
\hline Lazy in hanging it & 9 & 22.50 \\
\hline Weather is warm & 21 & 52.50 \\
\hline \multicolumn{3}{|c|}{$\begin{array}{l}\text { Noticed decline in malaria following } \\
\text { usage of ITN }\end{array}$} \\
\hline Yes & 348 & 96.10 \\
\hline No & 14 & 3.90 \\
\hline \multicolumn{3}{|c|}{$\begin{array}{l}\text { Would you recommend ITN use to } \\
\text { others }\end{array}$} \\
\hline Yes & 360 & 99.40 \\
\hline No & 2 & 0.60 \\
\hline \multicolumn{3}{|l|}{$\begin{array}{l}\text { Do you always get ITNs from the } \\
\text { hospitals }\end{array}$} \\
\hline Yes & 254 & 70.20 \\
\hline No & 108 & 29.80 \\
\hline \multicolumn{3}{|l|}{ Do they sell ITNs to you } \\
\hline Yes & 10 & 2.80 \\
\hline No & 352 & 97.20 \\
\hline
\end{tabular}


Table 4. Continued

\begin{tabular}{|c|c|c|}
\hline Variables & n & $\%$ \\
\hline \multicolumn{3}{|c|}{$\begin{array}{l}\text { If you were to buy an ITN, would you } \\
\text { be able to pay for it }\end{array}$} \\
\hline Yes & 330 & 91.20 \\
\hline No & 32 & 8.80 \\
\hline \multicolumn{3}{|c|}{$\begin{array}{l}\text { What cost would be considered } \\
\text { affordable (GHS) }\end{array}$} \\
\hline$<5$ & 92 & 25.40 \\
\hline $5-10$ & 150 & 41.40 \\
\hline $11-20$ & 120 & 33.10 \\
\hline \multicolumn{3}{|c|}{$\begin{array}{l}\text { Has the attitude of health personnel } \\
\text { made you refuse to get an ITN }\end{array}$} \\
\hline Yes & 13 & 3.60 \\
\hline No & 349 & 96.40 \\
\hline \multicolumn{3}{|c|}{$\begin{array}{l}\text { Are the health workers } \\
\text { discriminatory in distributing ITNs }\end{array}$} \\
\hline Yes & 16 & 4.40 \\
\hline No & 346 & 95.60 \\
\hline \multicolumn{3}{|c|}{$\begin{array}{l}\text { How long do you have to travel to get } \\
\text { an ITN }\end{array}$} \\
\hline Short & 282 & 77.90 \\
\hline Long & 80 & 22.10 \\
\hline \multicolumn{3}{|c|}{$\begin{array}{l}\text { Does the distance to an ITN } \\
\text { distribution site hinder you from } \\
\text { getting one }\end{array}$} \\
\hline Yes & 28 & 7.70 \\
\hline No & 33 & 92.30 \\
\hline
\end{tabular}

Table 4. Continued

\begin{tabular}{|c|c|c|}
\hline Variables & n & $\%$ \\
\hline \multicolumn{3}{|c|}{$\begin{array}{l}\text { Are the ITNs distribution sites } \\
\text { accessible to all }\end{array}$} \\
\hline Yes & 309 & 85.40 \\
\hline No & 53 & 14.60 \\
\hline \multicolumn{3}{|c|}{$\begin{array}{l}\text { Did the ITN distribution officers come } \\
\text { to your house for registration }\end{array}$} \\
\hline Yes & 309 & 85.40 \\
\hline No & 53 & 14.60 \\
\hline \multicolumn{3}{|c|}{$\begin{array}{l}\text { Did they discriminate against your } \\
\text { household }\end{array}$} \\
\hline Yes & 19 & 5.20 \\
\hline No & 343 & 94.80 \\
\hline \multicolumn{3}{|c|}{$\begin{array}{l}\text { Do you get a reaction whenever you } \\
\text { use an ITN }\end{array}$} \\
\hline Yes & 54 & 14.90 \\
\hline No & 308 & 85.10 \\
\hline \multicolumn{3}{|c|}{ Personal reactions after using ITNs } \\
\hline Body itching & 28 & 51.90 \\
\hline Body rashes & 17 & 31.50 \\
\hline Body sensations & 9 & 16.60 \\
\hline \multicolumn{3}{|c|}{$\begin{array}{l}\text { Do your cultural beliefs prevent you } \\
\text { from using ITNs }\end{array}$} \\
\hline Yes & 8 & 2.20 \\
\hline No & 364 & 97.80 \\
\hline
\end{tabular}

Table 5. Association between sociodemographic characteristics and utilization of insecticides treated mosquito bed nets (ITNs)

\begin{tabular}{|c|c|c|c|c|}
\hline \multirow[t]{2}{*}{ Variables } & \multirow[t]{2}{*}{ Total } & \multicolumn{2}{|c|}{ Do you use ITNs? } & \multirow[t]{2}{*}{ Statistical test } \\
\hline & & $\begin{array}{c}\text { Yes } \\
\text { n }(\%)\end{array}$ & $\begin{array}{c}\text { No } \\
\text { n }(\%)\end{array}$ & \\
\hline \multicolumn{5}{|l|}{ Age (years) } \\
\hline$<20$ & 72 & $71(98.6)$ & $1(1.4)$ & $\chi^{2}=5.4$ \\
\hline $20-29$ & 92 & $89(96.7)$ & $3(3.3)$ & $\mathrm{p}=0.14$ \\
\hline $30-39$ & 168 & $156(92.9)$ & $12(7.1)$ & \\
\hline$\geq 40$ & 30 & $27(90.0)$ & $3(10.0)$ & \\
\hline \multicolumn{5}{|l|}{ Education level } \\
\hline No formal education & 33 & $32(97.0)$ & $1(3.0)$ & $\chi^{2}=3.1$ \\
\hline Junior high school and below & 137 & $128(93.4)$ & $9(6.6)$ & $p=0.38$ \\
\hline Senior high school & 91 & $89(97.8)$ & $2(2.2)$ & \\
\hline Tertiary & 101 & $94(93.1)$ & $7(6.9)$ & \\
\hline
\end{tabular}


Table 5. Continued

\begin{tabular}{|c|c|c|c|c|}
\hline \multirow[t]{2}{*}{ Variables } & \multirow[t]{2}{*}{ Total } & \multicolumn{2}{|c|}{ Do you use ITNs? } & \multirow[t]{2}{*}{ Statistical test } \\
\hline & & $\begin{array}{c}\text { Yes } \\
\text { n (\%) }\end{array}$ & $\begin{array}{c}\text { No } \\
\text { n }(\%)\end{array}$ & \\
\hline \multicolumn{5}{|l|}{ Religion } \\
\hline Christianity & 235 & $220(93.6)$ & $15(6.4)$ & $\chi^{2}=1.8$ \\
\hline Islam & 125 & $121(96.8)$ & $4(3.2)$ & $\mathrm{p}=0.41$ \\
\hline Traditionalist & 2 & $2(100.0)$ & $0(0.0)$ & \\
\hline \multicolumn{5}{|l|}{ Marital status } \\
\hline Single & 2 & $30(90.9)$ & $3(9.1)$ & $\chi^{2}=3.1$ \\
\hline Cohabiting & 2 & $2(100.0)$ & $0(0.0)$ & $\mathrm{p}=0.54$ \\
\hline Married & 317 & $302(95.3)$ & $15(4.7)$ & \\
\hline Divorced & 6 & $5(83.3)$ & $1(16.7)$ & \\
\hline Separated & 4 & $4(100.0)$ & $0(0.0)$ & \\
\hline \multicolumn{5}{|c|}{ Area of residence } \\
\hline Rural & 189 & $183(96.8)$ & $6(3.2)$ & $\chi^{2}=3.4$ \\
\hline urban & 173 & $160(92.5)$ & $13(7.5)$ & $\mathrm{p}=0.04$ \\
\hline \multicolumn{5}{|c|}{ Average monthly income (GHS) } \\
\hline$<500$ & 181 & $170(93.9)$ & $11(6.1)$ & $\chi^{2}=46.4$ \\
\hline 500-1000 & 98 & $92(93.9)$ & $6(6.1)$ & $\mathrm{p}<0.001$ \\
\hline $1001-1500$ & 62 & $60(96.8)$ & $2(3.2)$ & \\
\hline $1501-2000$ & 15 & $15(100.0)$ & $0(0.0)$ & \\
\hline$>2000$ & 6 & $6(100.0)$ & $0(0.0)$ & \\
\hline
\end{tabular}

GHS: 1000 Ghanaian Cedis about US\$160.

Association between sociodemographic characteristics and utilization of ITNs

With regard to place of stay, $96.8 \%$ of respondents in rural and $92.5 \%$ in urban areas used ITNs, while $3.2 \%$ and $7.5 \%$ of respondents in rural and urban areas, respectively, did not use the treated nets. The study revealed a significant association between area of residence and utilization of ITNs $\left(\chi^{2}=3.4 ; p=0.04\right)$. Also, increasing average monthly income was associated with utilization of ITNs $\left(\chi^{2}=46.4 ; p<0.001\right)$ (Table 5).

\section{DISCUSSION}

This study aimed to assess the use of ITNs among pregnant women in the Kassena-Nankana East Municipality. The study revealed that almost all respondents had heard about ITNs. This is consistent with other studies conducted elsewhere. For instance, in the Ho municipality, Ghana, a study showed that $98.7 \%$ of pregnant women had heard about bed nets ${ }^{26}$. Amara ${ }^{27}$ revealed that, in the Greater Accra Region of Ghana, over $60 \%$ of the mothers with children aged $<5$ years had heard about ITNs. Also, in the Nanumba South District in the Northern Region of Ghana, over $80 \%$ of pregnant mothers had heard about bed nets ${ }^{10}$. In Nigeria, $93.2 \%$ of pregnant women were aware of bed nets ${ }^{28}$. These similarities are justified by the fact that, in Ghana and in most African countries, there have been focused attempts by the Ministry of Health, through the support of WHO and UNICEF, to provide education on malaria prevention. This is because malaria is among the key causes of maternal anemia. Maternal anemia is one of the leading causes of infant and maternal morbidity and mortality in Sub-Saharan Africa (SSA). Insecticides treated mosquito nets are the simplest most effective way of preventing malaria ${ }^{22}$. This, therefore, explains why most respondents in Africa are aware of ITNs.

The study revealed varied sources of information on ITNs including the media, health workers, friends, and relatives. However, the majority of the pregnant women heard about them from the media (tv, radio, and internet) followed by health workers. This is consistent with other studies conducted in Ghana where the majority of respondents had heard about ITNs through the media ${ }^{25}$. More people get information from the media because, in Ghana, there are a lot of sponsors for malaria advertisements and talk shows on radio and TV. In the Kassena-Nankana East municipality, 
there are two main radio stations with very wide coverage and a community radio. This could explain why the media are considered a major source of information on ITNs. Also, $74.9 \%$ of the pregnant women in this study had heard about ITNs through health workers, it was not the main source of information. This is, however, similar to a study conducted by Amara $^{27}$ where $80 \%$ of respondents had heard of ITNs from health professionals. During antenatal care (ANC) visits, pregnant women are educated on a variety of conditions including malaria. Those who attend ANC regularly might have heard about ITNs in the clinic. Given the varied sources of information, what we learn is that to be able to reach a wider coverage with information regarding ITNs and malaria prevention, there is a need to adopt multiple sources of delivery of information, so that those who may not be attending ANC regularly could still get reliable information on ITNs through radio, TV or internet.

The majority of the pregnant women in this study reported having obtained their ITNs from a health facility. According to Nungbaso et al. ${ }^{25}$, the majority of the respondents in the Tamale metropolis benefitted from the free distribution of bed nets from the health facilities. Even though the respondents are different, the policies regarding the free distribution of ITNs are often targeted at the general population with interest among pregnant women and children aged $<5$ years ${ }^{29}$.

About $90 \%$ of the respondents knew that ITNs were used to prevent malaria. Available literature in Ghana supports the current findings. For instance, $91.1 \%$ and $97.8 \%$ of the respondents in $\mathrm{Ho}^{26}$ and Greater Accra ${ }^{27}$, respectively, knew about the general usage of ITNs. However, in Nigeria, Musa $^{30}$ showed that only $36 \%$ of the respondents knew the correct usage of ITNs. This difference could be attributed to the geographical difference, beliefs, and sociocultural characteristics of the respondents.

The ownership of ITNs was determined as $97.8 \%$ in this study. The current findings are higher than the $71 \%$ reported in Western Kenya by Atieli et al. ${ }^{31}$ and $64.9 \%$ reported in Nigeria by Ezire et al. ${ }^{28}$. Though these studies indicate that the majority of their respondents owned ITNs, they were observed to be lower than the findings of the current studies. This suggests that the Ministry of Health of Ghana has adopted a robust method to distribute the ITNs.

The majority of the respondents indicated that they believed ITNs were effective. This is consistent with a study by Abokyi et al. ${ }^{32}$ where over $95 \%$ of respondents believed ITNs were very effective in preventing malaria. This is crucial in determining the utilization of ITNs because, if the population does not believe in the efficacy of ITNs, the patronage would be lower. This is evident by the $94.8 \%$ of pregnant women in this study using ITNs. In other studies, the majority of respondents said that they were using ITNs $^{10,31}$. However, Amara ${ }^{27}$ reported very low usage of ITNs. This could be attributed to the differences in government policies on free ITN distribution and behavioral and personal preferences of the respondents.

Though the use of ITNs was observed to be high in the study, only $47.8 \%$ were using ITNs every day. The actual utilization of ITNs is varied across the globe. For example, Atieli et al. ${ }^{31}$ showed that the majority used ITNs throughout the year, Bukari ${ }^{10}$ reported $34.4 \%$ actual utilization, and $19 \%$ were using ITNs in another study ${ }^{27}$. What this tells us is that ownership of ITNs does not always result in utilization due to sociocultural and logistic reasons. Some of the women having ITNS, do not use them all year round. For some of the respondents in this study, ITNs were used frequently only in the rainy season. This is because the cases of malaria often increase during rainy periods ${ }^{25}$. Some also reported dissatisfaction with the use of ITNs and as such resort to other preventive measures. This is supported by available literature, where some people prefer other methods of protection such as mosquito coils, repellents, electric fans, etc ${ }^{33}$. From the foregoing, the use of other preventive measures could be a reason for the difference between ownership and actual utilization of ITNs.

The study revealed a wide variety of challenges such as ITNs being inaccessible, side effects, ITNs being warm, among others. This is similar to a study where respondents currently using ITNs complained of scarcity of new nets, difficulty in getting chemicals for re-treatment of nets, nonavailability of quality ITNs for sale, resulting in disuse of ITNs ${ }^{26}$. Also, the cost of the nets was featured among the barriers to effective utilization of ITNs. In Ghana, there are free distributions of ITNs at antenatal care (ANC) units, child welfare clinics (CWC), postnatal care (PNC) service centers as well as household distributions. The authors do not understand why issues of cost and accessibility are being raised by the respondents. These revelations by the respondents are sensitive and as such require further studies on the reasons for not using ITNs, using a mixed-method approach to bring in-depth understanding to these issues especially among those who cite cost as a barrier to ITN utilization.

The study also showed a significant association between area of residence and use of ITNs. This is similar to in the Upper West Region, Ghana where pregnant women in urban areas tend to use ITNs more than their counterparts in the rural setting ${ }^{34}$. In relation to the above, increasing average monthly income is associated with utilization of ITNs. This is consistent to a study in Northern ${ }^{23}$ and a systematic review in Sub-Sahara Africa ${ }^{35}$ where higher wealth index is associated with higher ITN ownership and usage, and vice versa. However, Garcia-Basteiro et al. ${ }^{36}$ did not establish any association between wealth index and ITN ownership and use. This means that, depending on the unique characteristics of each area and the tactics employed to deploy ITNs, the impoverished and relatively well-off may gain differentially. Often, the person with higher wealth index stays in the urban areas which are accessible and could be reached during distribution of ITNS. Also, people with a high 
socioeconomic class typically have access to other measures for preventing malaria. Whilst it is important to evenly distribute ITNs, extra efforts are required to reach the hardto-reach rural folk and the poor.

\section{Limitations}

As with self-reported surveys, our study is subject to information bias coupled with our inability to confirm the responses given. The study does, however, provide population-based data on ITN use among pregnant women in the study area. This can be relied on by agencies, including the Ministry of Health, Ghana Health Services, and other stakeholders for informed targeted public health interventions.

\section{CONCLUSIONS}

The study revealed a high awareness and knowledge of ITNs. Though the majority of the respondents owned Insecticides Treated Mosquito Nets (ITNs), it did not translate to effective utilization of ITNs among pregnant women. Thus, distribution of ITNs to pregnant women is not enough, there is the need to establish practical measures to ensure that persons who have the bed nets sleep under them. The free distribution of ITNs for the majority means that most people obtained ITNs. However, some persons whose residence were hard to reach due to bad roads are often left out of the free distribution of ITNs. They are therefore compelled to buy ITNs, which they think are very expensive. To resolve this, we recommend to the Ghana Health Service to train volunteers at local level to aid in the distributions of bed nets.

\section{REFERENCES}

1. Dodd R, Hill P, Huntington D. Strengthening country office capacity to support sexual and reproductive health in the new aid environment: Report of a technical consultation meeting: wrap-up assessment of the 2008-2011 UNFPAWHO collaborative project. World Health Organization; 2011. Accessed November 30, 2021. http://apps.who.int/ iris/bitstream/handle/10665/70737/WHO_RHR_11.29_eng. pdf

2. World malaria report 2019. World Health Organization; 2019. Accessed November 30, 2021. https://apps.who.int/ iris/rest/bitstreams/1262394/retrieve/

3. Aluko JO, Oluwatosin AO. Utilization of insecticide treated nets during pregnancy among postpartum women in Ibadan, Nigeria: a cross-sectional study. BMC Pregnancy Childbirth. 2012;12(1):21. doi:10.1186/1471-2393-12-21

4. Global Partnership to Roll Back Malaria. The African Summit on Roll Back Malaria, Abuja, Nigeria, April 25 2000. World Health Organization; 2000. Accessed November 30, 2021. https://apps.who.int/iris/bitstream/handle/10665/67815/ WHO_CDS_RBM_2000.17.pdf

5. Mueller DH, Wiseman V, Bakusa D, Morgah K, Daré A, Tchamdja P. Cost-effectiveness analysis of insecticide-treated net distribution as part of the Togo Integrated Child Health
Campaign. Malar J. 2008;7(1):73. doi:10.1186/1475-2875-7-73

6. Ghana Multiple Indicator Cluster Survey with an Enhanced Malaria Module and Biomarker, 2011, Final Report: MONITORING THE SITUATION OF CHILDREN AND WOMEN IN GHANA. Ghana Statistical Service; 2012. Accessed November 30, 2021. https://www.dhsprogram.com/pubs/ pdf/FR262/FR262.pdf

7. Kebede DL, Hibstu DT, Birhanu BE, Bekele FB. Knowledge, Attitude and Practice Towards Malaria and Associated Factors in Areka Town, Southern Ethiopia: CommunityBased CrossSectional Study. J Trop Dis. 2017;5(3):1000240. doi:10.4172/2329-891X.1000240

8. Inungu JN, Ankiba N, Minelli M, et al. Use of InsecticideTreated Mosquito Net among Pregnant Women and Guardians of Children under Five in the Democratic Republic of the Congo. Malar Res Treat. 2017;5923696:1-10. doi:10.1155/2017/5923696

9. Yassin IM, Rosnah S, Osman M. Factors Influencing the Usage of Insecticide Treated Mosquito Nets among Pregnant Women. International Journal of Health Research. 2010;3(3):139-144. doi:10.4314/ijhr.v3i3.70278

10. Bukari MK. Ownership and utilization of insecticide treated nets (ITNS) among pregnant women and children under five years in the prevention of malaria in the Nanumba South District of the Northern Region of Ghana. Thesis. Kwame Nkrumah University of Science and Technology; 2015.

11. Ahorlu CK, Koram KA, Ahorlu C, de Savigny D, Weiss MG. Sociocultural determinants of treatment delay for childhood malaria in southern Ghana. Trop Med Int Health. 2006;11(7):10221031. doi:10.1111/j.1365-3156.2006.01660.x

12. Bauserman M, Conroy AL, North K, Patterson J, Bose C, Meshnick S. An overview of malaria in pregnancy. Semin Perinatol. 2019;43(5):282-290. doi:10.1053/j.semperi.2019.03.018

13. Ghana: Malaria Operational Plan FY 2020. US President's Malaria Initiative; 2020. Accessed November 30, 2021. https://d1u4sg1s9ptc4z.cloudfront.net/uploads/2021/03/ fy-2020-ghana-malaria-operational-plan.pdf

14. WHO policy brief for the implementation of intermittent preventive treatment of malaria in pregnancy using sulfadoxine-pyrimethamine (IPTp-SP). World Health Organization; 2013. April, 2013. Updated January 2014. Accessed November 30, 2021. https://www.who.int/ malaria/publications/atoz/iptp-sp-updated-policy-brief24jan2014.pdf

15. Kanmiki EW, Bawah AA, Agorinya I, et al. Socio-economic and demographic determinants of under-five mortality in rural northern Ghana. BMC Int Health Hum Rights. 2014;14(1):24. doi:10.1186/1472-698X-14-24

16. van Eijk AM, Hill J, Alegana VA, et al. Coverage of malaria protection in pregnant women in sub-Saharan Africa: a synthesis and analysis of national survey data. Lancet Infect Dis. 2011;11(3):190-207. doi:10.1016/S1473-3099(10)70295-4

17. Baume CA, Franca-Koh AC. Predictors of mosquito net use in Ghana. Malar J. 2011;10(1):265. doi:10.1186/1475-2875-10-265 18. Manu G, Boamah-Kaali EA, Febir LG, Ayipah E, Owusu-Agyei 
S, Asante KP. Low Utilization of Insecticide-Treated Bed Net among Pregnant Women in the Middle Belt of Ghana. Malar Res Treat. 2017;(7481210):1-7. doi:10.1155/2017/7481210

19.2015 Annual Report: National Malaria Control Programme. Republic of Ghana; 2016. February, 2016. Accessed November 30, 2021. https://web.archive.org/ web/20200226165913/https://www.ghanahealthservice. org/downloads/NMCP_2015_ANNUAL_REPORT.pdf

20. Ghana Malaria Indicator Survey 2016. Ghana Statistical Service; 2017. May, 2017. Accessed November 30, 2021. https://dhsprogram.com/pubs/pdf/MIS26/MIS26.pdf

21. Ghana Demographic and Health Survey, 2014. Ghana Statistical Service; 2015. October, 2015. Accessed November 30, 2021. https://dhsprogram.com/pubs/pdf/fr307/fr307.pdf

22. Ernst KC, Erly S, Adusei C, et al. Reported bed net ownership and use in social contacts is associated with uptake of bed nets for malaria prevention in pregnant women in Ghana. Malar J. 2017;16(1):13. doi:10.1186/s12936-016-1660-4

23. Kanmiki EW, Awoonor-Williams JK, Phillips JF, et al. Socioeconomic and demographic disparities in ownership and use of insecticide-treated bed nets for preventing malaria among rural reproductive-aged women in northern Ghana. PLoS One. 2019;14(1):e0211365. doi:10.1371/journal.pone.0211365

24. Snedecor GW, Cochran WG. Statistical methods, 8th ed. Iowa State University Press; 1989;71-82.

25. Nungbaso AM, Ziba FA, Nukpezah RN, et al. Awareness and Use of Insecticide-Treated Bed Nets (ITNs) among Students in the Second Cycle Institutions in the Tamale Metropolis of Northern Region Ghana. Asian Journal of Research in Nursing and Health. 2021;4(4):1-12. Accessed November 30, 2021. https://www.journalajrnh.com/index.php/AJRNH/article/ view/30141

26. Nyavor KD, Kweku M, Agbemafle I, et al. Assessing the ownership, usage and knowledge of Insecticide Treated Nets (ITNs) in Malaria Prevention in the Hohoe Municipality, Ghana. Pan Afr Med J. 2017;28:67. doi:10.11604/pamj.2017.28.67.9934.

27. Amara R. Factors Influencing Utilization of Insecticide Treated Nets Among Children Under Five Years In Kpone-OnSea Township of Greater Accra Region of Ghana. University of Ghana; 2017. Accessed November 30, 2021. http://ugspace. ug.edu.gh/handle/123456789/35420

28. Ezire 0, Adebayo SB, Idogho O, Bamgboye EA, Nwokolo E. Determinants of use of insecticide-treated nets among pregnant women in Nigeria. Int J Womens Health. 2015;7:655-661. doi:10.2147/IJWH.S77807

29. Owusu Adjah ES, Panayiotou AG. Impact of malaria related messages on insecticide-treated net (ITN) use for malaria prevention in Ghana. Malar J. 2014;13(1):123. doi:10.1186/1475-2875-13-123

30. Musa OI, Salaudeen GA, Jimoh RO. Awareness and use of insecticide treated nets among women attending antenatal clinic in a northern state of Nigeria. J Pak Med Assoc. 2009;59(6):354-358. Accessed November 30, 2021. https:// jpma.org.pk/article-details/1713?article_id=1713

31. Atieli HE, Zhou G, Afrane Y, et al. Insecticide-treated net (ITN) ownership, usage, and malaria transmission in the highlands of western Kenya. Parasit Vectors. 2011;4(1):113. doi:10.1186/1756-3305-4-113

32. Abokyi LN, Asante KP, Mahama E, et al. Use of Antimalarial in the Management of Fever during a Community Survey in the Kintampo Districts of Ghana. PLoS One. 2015;10(11):e0142106. doi:10.1371/journal.pone.0142106

33. Marotti AR. Methods of Malaria Prevention in Ghana, Africa: An Exhaustive Literature Review Literature Review. Thesis. University of Arkansas; 2021. Accessed November 30, 2021. https://scholarworks.uark.edu/cgi/viewcontent. cgi?article $=1133 \&$ context $=$ nursuht

34. Dinkpee A. FACTORS INFLUENCING THE UTILIZATION OF INSECTICIDE TREATED BED NETS (ITN) BY PREGNANT WOMEN IN THE WA EAST DISTRICT OF UPPER WEST REGION. Dissertation. University of Ghana; 2018. Accessed November 30, 2021. http://ugspace.ug.edu.gh/ handle/123456789/26343

35.Singh M, Brown G, Rogerson SJ. Ownership and use of insecticide-treated nets during pregnancy in subSaharan Africa: a review. Malar J. 2013;12:268. doi:10.1186/1475-2875-12-268

36. García-Basteiro AL, Schwabe C, Aragon C, et al. Determinants of bed net use in children under five and household bed net ownership on Bioko Island, Equatorial Guinea. Malar J. 2011;10(1):179. doi:10.1186/1475-2875-10-179

\section{ACKNOWLED GEMENTS}

We are grateful to the Kassena Nankana East Municipal Health Directorate and all facility authorities for supporting and facilitating our data collection processes. In addition, we are indebted to the participants who voluntarily decided to share their experiences to enrich this research.

CONFLICTS OF INTEREST

The authors have completed and submitted the ICMJE Form for Disclosure of Potential Conflicts of Interest and none was reported.

FUNDING

There was no source of funding for this research.

ETHICAL APPROVAL AND INFORMED CONSENT

This research was approved on April 23, 2021 by the Joint Ethics Committee of the School of Public Health and School of Allied Health Sciences, University for Development Studies, Tamale, and by the Municipal Health Directorate. All participants provided verbal and written informed consent for participation in the study. 
DATA AVAILABILITY

The data supporting this research can be found in the Supplementary file.

PROVENANCE AND PEER REVIEW

Not commissioned; externally peer reviewed.

Public Health Toxicol 2021:1(2):9 